Research Article

\title{
Comparison of 27-Gauge and 25-Gauge Microincision Vitrectomy Surgery for the Treatment of Vitreoretinal Disease: A Systematic Review and Meta-Analysis
}

\author{
Jinlan Ma ${ }^{D},{ }^{1}$ Qing Wang, ${ }^{1}$ and Haoyu Niu ${ }^{2}$ \\ ${ }^{1}$ Department of Ophthalmology, Affiliated Hospital of Qinghai University, No. 29 of Tongren Road, Xining 810000, \\ Qinghai Province, China \\ ${ }^{2}$ Medical College of Qingha University, No. 16 of Konglun Road, Xining 810000, Qinghai Province, China
}

Correspondence should be addressed to Jinlan Ma; majinlan0108@126.com

Received 1 June 2020; Accepted 4 August 2020; Published 18 August 2020

Guest Editor: Rodolfo Mastropasqua

Copyright (c) 2020 Jinlan Ma et al. This is an open access article distributed under the Creative Commons Attribution License, which permits unrestricted use, distribution, and reproduction in any medium, provided the original work is properly cited.

Background. We performed a systematic review and meta-analysis to evaluate the safety and effectiveness of 27-gauge (27-G) microincision vitrectomy surgery (MIVS) compared with 25-guage (25-G) MIVS for the treatment of vitreoretinal disease. Methods. A systematic electronic search was conducted in March 2020 in PubMed, Embase, and the Cochrane library. Eligible criteria for including studies were controlled trials comparing $27-\mathrm{G}$ vitrectomy with $25-\mathrm{G}$ vitrectomy in patients with vitreoretinal disease. The main outcomes included operation time; best corrected visual acuity (BCVA) in logMAR; postoperative intraocular pressure (IOP); primary anatomical success rate for rhegmatogenous retinal detachment (RRD) cases and postoperative central macular thickness (CMT) for idiopathic epiretinal membrane (ERM) cases; intraoperative/postoperative complications. Odds ratio (OR) and mean difference (MD) were synthesized under fixed or random effects models. Results. Eleven studies enrolling 940 eyes were identified. Among those 11 studies, six studies were on the treatment of RRD and five studies were on the treatment of ERM, so subgroup analyses were conducted. The total pooled results indicated that $27-\mathrm{G}$ surgery system had obvious advantages in improving BCVA at six months after the vitrectomy $(P=0.004)$ and reducing intraoperative/postoperative complications $(P=0.03)$. However, the mean operation time was significantly longer by three minutes for $27-\mathrm{G}$ compared with $25-\mathrm{G}$ vitrectomy $(P=0.002)$. In subgroup analyses, for the treatment of ERM cases, $27-\mathrm{G}$ group was associated with less complications and longer operation time. However, for the treatment of RRD cases, 27-G groups and 25-G groups were comparable in operation time, postoperative BCVA, postoperative IOP, and primary anatomical success rate. Conclusions. This meta-analysis confirmed that $27-$ G MIVS was an effective and safe surgical system compared with 25-G MIVS for the treatment of RRD and ERM cases, even though $27-\mathrm{G}$ system needs a longer surgical time.

\section{Introduction}

Microincision vitrectomy surgery (MIVS) was first introduced by Machemer in the early 1970s [1], and this technique represented a new era in ophthalmology. Since that moment, 20-gauge (20-G), 23-G, and 25-G surgery system were applied to vitrectomy [2-4]. There was no doubt that current MIVS with $25-\mathrm{G}$ or $23-\mathrm{G}$ instruments had simplified vitrectomy procedure and had provided numerous potential advantages over traditional $20-\mathrm{G}$ surgery [5-10]. It was confirmed that smaller wounds could reduce the intraocular inflammation $[9,11]$, shorten recover time [7, 12], and decrease intraoperative/postoperative complications $[12,13]$. In 2010s, Oshima et al. first described 27-G MIVS for the treatment of vitreoretinal diseases [14]. In the beginning, the 27-G vitrectomy was conducted mainly for simple cases such as epiretinal membrane (ERM), idiopathic macular holes, and vitreous hemorrhage [15-17]; recently, indications for $27-\mathrm{G}$ vitrectomy have since been expanded to more complicated conditions, including proliferative 
diabetic retinopathy, rhegmatogenous retinal detachment (RRD), and proliferative vitreoretinopathy [18-20]. Many studies have shown the advantages of 27-G MIVS in terms of patients' comfort, convalescence, inflammatory response, and visual recovery in the ERM surgery compared with traditional 25-G vitrectomy [15, 17, 21-23]. However, some studies concluded that $27-\mathrm{G}$ vitrectomy requires longer operation time for the treatment of RRD cases because of the lower flow rate. Moreover, 27-G vitrectomy induced more postoperative inflammation because of sutureless wounds [20, 24-26].

We performed this meta-analysis to evaluate the feasibility, safety, and effectiveness of 27-G instrument for uncomplicated macular diseases such as ERM and complicated peripheral vitreoretinal disorders such as RRD. This study would expand our current knowledge of the safety and effectiveness of the 27-G MIVS.

\section{Methods}

2.1. Search Strategy and Inclusion Criteria. This meta-analysis was conducted in accordance with the Cochrane Handbook for Systematic Reviews of Interventions and Preferred Items for Systematic Reviews and Meta-Analysis (PRISMA) Statement. Two researchers independently performed the literature search in the PubMed, the Cochrane Library, and EMBASE database until March 2020. The search used the following keyword strings: "27-gauge," "25gauge," and "vitrectomy" in various combinations with the language limited to English. The reference lists of case reports, studies, and review articles were also reviewed for any additional citations. To increase sample size, we included both control trials and observational studies. Studies that appeared twice, or focused on other outcomes based on the same study group, were removed as the duplicated publications. All relevant articles identified through the search were scanned based on the title, keywords, and abstract by at least two investigators and were rejected in the initial screening if the article clearly did not meet the inclusion criteria. When a title/abstract could not be rejected with certainty, full texts of retrieved publications were reviewed and evaluated.

2.2. Inclusion Criteria. Studies were included if they (i) compared 27-G with 25-G vitrectomy for vitreoretinal disease, (ii) randomized controlled trials (RCTs), cohort, case-control or cross-sectional studies with at least four weeks' followup, and (iii) contained sufficient information of treatment outcome.

2.3. Data Extraction. The following information were extracted by the investigators independently from the published reports, using a standardized protocol and reporting form: first author's last name, year of publication, country of origin, number of enrolled eyes, mean age of patients, vitreoretinal disease, followup information, and related complications.
2.4. Outcome Measures. The main outcomes for this metaanalysis included operation time; best corrected visual acuity (BCVA) in logMAR at six months post-vitrectomy (POM6); intraocular pressure (IOP) at postoperative day 1 (POD1); primary anatomical success rate for RRD cases; postoperative central macular thickness (CMT) for ERM cases and intraoperative/postoperative complications. Complications were defined as adverse events result from surgery such as hypotony, intraocular hypertension, wound suture because of leakage, recurrent $\mathrm{RD}$, vitreous hemorrhage $(\mathrm{VH})$, iatrogenic retinal breaks (IRBs), and other surgery-related complications.

2.5. Assessment of Methodology Quality. Reviewers independently assessed the qualities of the included trials using a system which was previously reported by Downs and Blacks [27]. This system was appropriate for both randomized and nonrandomized studies. The system comprises 27 items distributed among five subscales regarding reporting (10 items), external validity (3 items), bias (7 items), confounding (6 items), and power (1 item). The total maximum score was 31 . The studies with a quality score of more than 16 were considered to have adequate quality. Any discrepancy in the quality assessment between the two observers was discussed and a consensus was reached.

2.6. Statistical Analysis. Data were processed by REVMAN (Version 5.3; The Cochrane Collaboration, Copenhagen, Denmark). We calculated the mean difference (MD) for the continuous outcome along with 95\% confidence intervals (CIs) by inverse variance method. For discontinuous outcomes, the summary odds ratios (ORs) were calculated by Mantel-Haenszel method. $P<0.05$ was considered statistically significant, and 95\% confidence intervals (CIs) were reported.

The between-study heterogeneity was tested by the chisquare-based $\left(\chi^{2}\right)$ Cochran's statistics and the inconsistency index $\left(I^{2}\right)$ [28], which indicated the proportion of variability across studies due to heterogeneity rather than sample error. In the presence of substantial heterogeneity $\left(I^{2}>45 \%\right)$, the random effect model (REM) was adopted as the pooling method; otherwise, when $I^{2}<45 \%$, the fixed effect model (FEM) was adopted as the pooling method.

The leave-one-out sensitivity analysis was performed using $I^{2}>50 \%$ as the criteria for evaluating the key studies with a substantial impact on between-study heterogeneity. Subgroup analyses were conducted for RRD cases and ERM cases in order to reduce heterogeneity. A funnel plot was performed to look for evidence of publication bias. The funnel plot should be asymmetric when there is publication bias or symmetric in the case of no publication bias.

\section{Results}

3.1. Literature Search. A total of 190 studies were initially identified. The abstracts were reviewed, and 21 studies with potentially relevant trials were reviewed in their entirety. Subsequently, eight studies were excluded because they did 


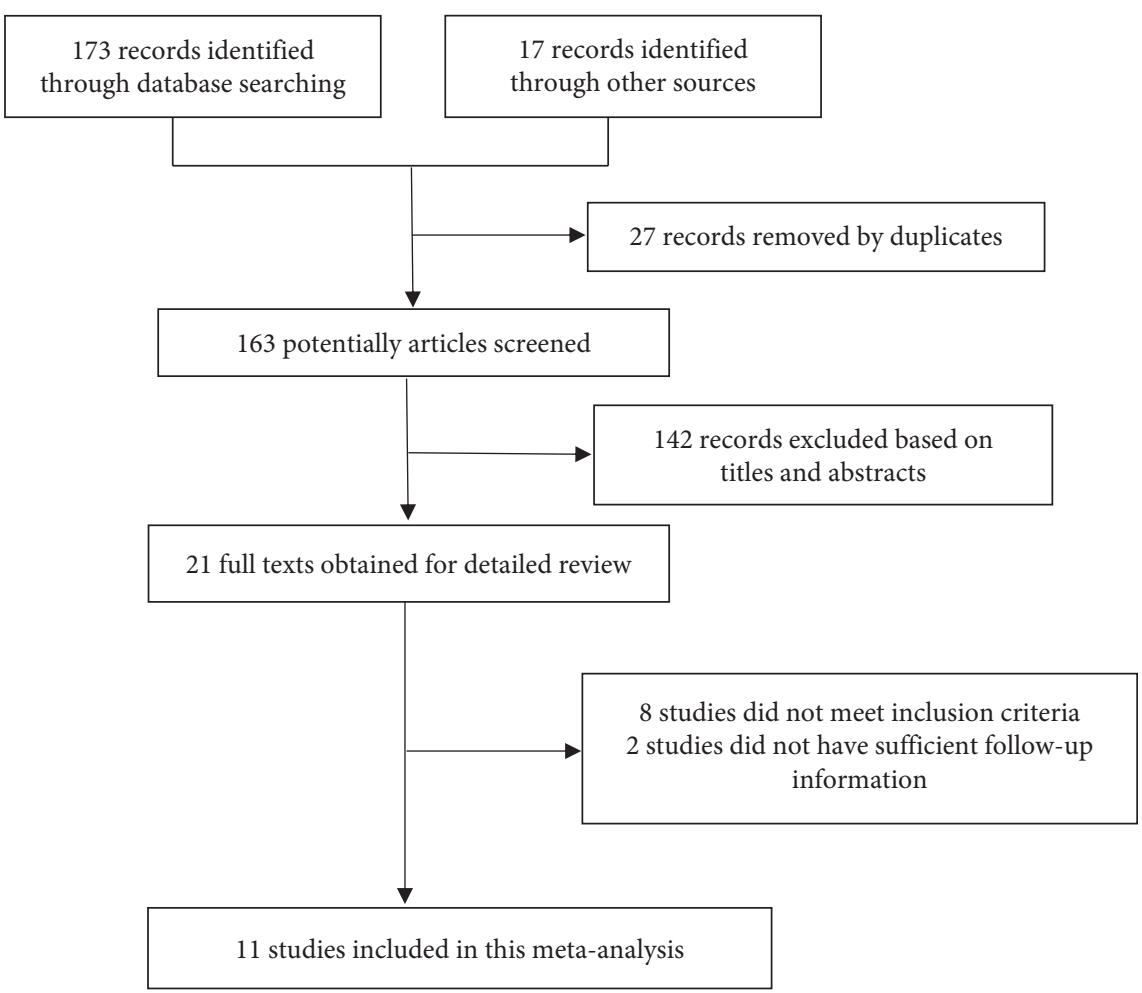

Figure 1: Flow diagram of literature search and study selection.

not have sufficient followup information and two studies were excluded because of design heterogeneity (Figure 1). Finally, a total of 11 studies were included in this metaanalysis.

3.2. Characteristics and Quality of Included Studies. Table 1 lists the characteristics of the included studies. These studies were published between 2015 and 2019. Seven studies $[15,21-24,26,31]$ were designed as prospective randomized/ nonrandomized comparative study and four studies $[17,25,29,30]$ were retrospective randomized/nonrandomized comparative study. Five trials [15, 17, 21, 24, 29] enrolled 554 eyes which were conducted on ERM and six studies $[22,23,25,26,30,31]$ enrolled 386 eyes which were conducted on RRD. In total, 940 eyes were included in this meta-analysis; 439 eyes were assigned to the $27-G$ vitrectomy group and 501 eyes to the $25-\mathrm{G}$ group. The duration of followup ranged from one to twelve months. The mean age in each study was not significant difference between the 27-G and $25-\mathrm{G}$ group. All the patients underwent vitrectomy with Constellation vision system.

For the Downs and Blacks score, all studies were over 16 which means the quality of these studies were adequate.

3.3. Operation Time. Ten studies compared operation time between 27-G and 25-G group, the total pooled result showed that $27-\mathrm{G}$ vitrectomy needs approximately three minutes longer than $25-\mathrm{G}$, and the difference was statistically significant $(\mathrm{MD}=2.89 ; 95 \% \mathrm{CI}: 1.07,4.72 ; P=0.002)$ (Figure 2). There was moderate heterogeneity among studies
$\left(I^{2}=56 \%, P=0.02\right)$, and so, REM meta-analysis was used. In order to explore the potential sources of heterogeneity, sensitivity analysis (via excluding the studies one by one) was proceeded. After the Takashina et al. study [17] was excluded, the heterogeneity almost disappeared $\left(I^{2}=19 \%\right.$, $P=0.27 ; \mathrm{MD}=3.64 ; 95 \% \mathrm{CI}: 2.29,4.99 ; P<0.001)$, which indicated this study can be identified as the main contributor of heterogeneity. We reevaluated the study of Takashina et al. in terms of design, statistics, and selection bias and did not find anything wrong. In fact, this study did not influence the final pooled result.

Subgroup analyses were conducted on RRD and ERM. For the treatment of ERM, the operation time was approximately $2.5 \mathrm{~min}$ longer in $27-\mathrm{G}$ group, and the difference was significant $(\mathrm{MD}=2.49 ; 95 \% \mathrm{CI}$ : $0.26,4.73$; $P=0.01)$. However, the difference was not significant for the treatment of $\mathrm{RRD}(\mathrm{MD}=3.12 ; 95 \% \mathrm{CI}:-0.95,7.19 ; P=0.13)$.

3.4. Visual Outcome. Data on BCVA were provided in eight studies. The pooled result indicated that the $27-\mathrm{G}$ group had a favorable response in visual recovery at six months after vitrectomy, and the difference was significant $(\mathrm{MD}=-0.03$; 95\% CI: $-0.06,-0.01 ; P=0.004$ ) (Figure 3). Random effect model was adopted as the pooling method because of obvious heterogeneity in the ERM subgroup $\left(I^{2}=45 \%\right)$. In ERM subgroup, BCVA at six months after vitrectomy was comparable between 27-G group and 25-G group $(\mathrm{MD}=-0.04 ; 95 \% \mathrm{CI}:-0.08,0.00 ; P=0.06)$. The sensitivity analysis showed the study of Mitsui $\mathrm{K}$ was the main source of heterogeneity. However, there was no statistics and selection bias in this study. In the RRD subgroup, there was no 
TABLE 1: Characteristics of involved studies.

\begin{tabular}{|c|c|c|c|c|c|c|c|}
\hline Included studies & Design & Disease & Location & $\begin{array}{c}\text { No. of } \\
\text { eyes } 27 \mathrm{G} / \\
25 \mathrm{G} \\
\end{array}$ & $\begin{array}{c}\text { Age (year) } \\
\text { mean } \pm \text { SD 27G/ } \\
25 \mathrm{G}\end{array}$ & $\begin{array}{l}\text { Followup } \\
\text { (months) }\end{array}$ & $\begin{array}{c}\text { Complications (eyes) } \\
27 \mathrm{G} / 25 \mathrm{G}\end{array}$ \\
\hline $\begin{array}{l}\text { Reibaldi et al. } \\
\text { [21] }\end{array}$ & $\begin{array}{l}\text { Prospective randomized } \\
\text { comparative study }\end{array}$ & ERM & Italy & $40 / 39$ & $\begin{array}{c}66 \pm 6 / 64 \pm 6 \\
P=0.14\end{array}$ & 12 & $\begin{array}{c}\text { IRB: } 0 / 3 \\
\text { VH: } 2 / 3 \\
\text { Hypotony: } 1 / 2 \\
\text { ERM recurrence: } 3 / 2\end{array}$ \\
\hline Mitsuiet al. [15] & $\begin{array}{c}\text { Prospective } \\
\text { nonrandomized } \\
\text { comparative study }\end{array}$ & ERM & Japan & $32 / 36$ & $\begin{array}{c}68.9 \pm 5.3 / \\
65.4 \pm 11.4 \\
P=0.33\end{array}$ & 6 & Hypotony: $3 / 4$ \\
\hline $\begin{array}{l}\text { Takashina et al. } \\
{[17]}\end{array}$ & $\begin{array}{l}\text { Retrospective randomized } \\
\text { comparative study }\end{array}$ & ERM & Japan & $59 / 88$ & $\begin{array}{c}72.9 \pm 6.3 / 71.3 \pm 7.9 \\
P: \text { NA }\end{array}$ & 1 & NA \\
\hline Rizzo et al. [9] & $\begin{array}{c}\text { Prospective } \\
\text { nonrandomized } \\
\text { comparative study }\end{array}$ & RRD & Italy & $20 / 20$ & $\begin{array}{c}64.7 \pm 9.7 / \\
62.4 \pm 9.8 \\
P: \text { NA }\end{array}$ & 6 & $\begin{array}{c}\text { IRB: } 2 / 1 \\
\text { Choroidal } \\
\text { detachment: } 1 / 0 \\
\text { RD: } 2 / 3 \\
\text { Intraocular } \\
\text { hypertension: } 1 / 2 \\
\text { RD: } 0 / 1\end{array}$ \\
\hline $\begin{array}{l}\text { Naruse et al. } \\
{[29]}\end{array}$ & $\begin{array}{c}\text { Retrospective } \\
\text { nonrandomized clinical } \\
\text { trial }\end{array}$ & ERM & Japan & $100 / 100$ & $\begin{array}{c}67.6 \pm 9.6 / \\
69.4 \pm 8.9 \\
P=0.25\end{array}$ & 6 & $\begin{array}{c}\text { VH: } 1 / 1 \\
\text { Hypotony: } 2 / 6 \\
\text { Intraocular } \\
\text { hypertension: } 4 / 10 \\
\text { RD: } 1 / 1\end{array}$ \\
\hline $\begin{array}{l}\text { Romanoet al. } \\
{[23]}\end{array}$ & $\begin{array}{l}\text { Prospective randomized } \\
\text { comparative study }\end{array}$ & RRD & Italy & $15 / 15$ & $\begin{array}{c}58 \pm 8 / 59 \pm 11 \\
P=0.82\end{array}$ & 6 & $\begin{array}{c}\mathrm{VH}: 1 / 0 \\
\text { Intraocular } \\
\text { hypertension: } 0 / 2 \\
\text { RD: } 3 / 3\end{array}$ \\
\hline Liet al. [30] & $\begin{array}{l}\text { Retrospective } \\
\text { nonrandomized clinical } \\
\text { trial. }\end{array}$ & RRD & China & $34 / 58$ & $\begin{array}{c}58.5 \pm 13.3 / \\
54.1 \pm 12.5 \\
P=0.1\end{array}$ & 6 & $\begin{array}{c}\text { IRB: } 1 / 2 \\
\text { Hypotony: } 0 / 1 \\
\text { Intraocular } \\
\text { hypertession: } 0 / 1\end{array}$ \\
\hline $\begin{array}{l}\text { Lubinski et al } \\
\text { [24] }\end{array}$ & $\begin{array}{l}\text { Prospective randomized } \\
\text { comparative study }\end{array}$ & ERM & Poland & $30 / 30$ & $\begin{array}{c}65.40 \pm 4.29 / \\
67.50 \pm 4.18 \\
P=0.052\end{array}$ & 6 & $\begin{array}{c}\text { RD: } 1 / 1 \\
\text { Macular hole: } 1 / 0 \\
\text { Hypotony: } 3 / 7\end{array}$ \\
\hline $\begin{array}{l}\text { Otsuka et al. } \\
{[25]}\end{array}$ & $\begin{array}{c}\text { Retrospective } \\
\text { nonrandomized clinical } \\
\text { trial }\end{array}$ & RRD & Japan & $30 / 32$ & $\begin{array}{c}59 \pm 13 / 55 \pm 9 \\
P=0.15\end{array}$ & 6 & RD: $1 / 2$ \\
\hline $\begin{array}{l}\text { Sborgia et al. } \\
{[31]}\end{array}$ & $\begin{array}{l}\text { Prospective randomized } \\
\text { comparative study }\end{array}$ & RRD & Italy & $42 / 46$ & $\begin{array}{c}59.9 \pm 9.2 / 61.7 \pm 8.7 \\
P=0.35\end{array}$ & 12 & $\begin{array}{c}\text { RD: } 4 / 2 \\
\text { Choroidal } \\
\text { detachment: } 1 / 0 \\
\text { ERM: } 5 / 2 \\
\text { CME: } 2 / 1 \\
\text { RD: } 4 / 3\end{array}$ \\
\hline Veritti et al. [26] & $\begin{array}{l}\text { Prospective randomized } \\
\text { comparative study }\end{array}$ & RRD & Italy & $37 / 37$ & $\begin{array}{c}63.9 \pm 13.5 / \\
63.1 \pm 12.5 \\
P=0.8\end{array}$ & 6 & $\begin{array}{c}\text { Hypotony: } 0 / 2 \\
\text { Intraocular } \\
\text { hypertension: } 4 / 5 \\
\text { Wound suture: } 3 / 11\end{array}$ \\
\hline
\end{tabular}

CME: cystoid macular edema; ERM: epiretinal membrane; IRBs: iatrogenic retinal breaks; RRD: rhegmatogenous retinal detachment; VH: vitreous hemorrhage; hypotony was defined as IOP $<6 \mathrm{mmHg}$ and intraocular hypertension was defined as IOP $>21 \mathrm{mmHg}$.

obvious difference between 27-G group and 25-G group $\left(\mathrm{MD}=-0.08 ; 95 \% \mathrm{CI}:-0.15,0.00 ; P \geq 0.05, I^{2}=0 \%\right)$.

3.5. IOP. Eight studies recorded IOP on the first day postoperative (POD1). 27-G group and 25-G group had the same effect in controlling postoperative IOP and there were no significant differences $(\mathrm{MD}=0.53$; 95\% CI: $-1.49,2.54$; $P=0.61$ ). In the subgroup analysis, IOP on POD1 were comparable between 27-G and 25-G group for the RRD cases
$(\mathrm{MD}=-0.36 ; 95 \% \mathrm{CI}:-1.36,0.63 ; P=0.47)$ and $\mathrm{ERM}$ cases $(\mathrm{MD}=0.83 ; 95 \% \mathrm{CI}:-2.05,3.7 ; P=0.57)$. Significant heterogeneity was found $\left(I^{2}=92 \%\right)$, so random effects were used. The study of Lubinski et al. [24] was the main contributor of heterogeneity, and after reevaluating this study, we found nothing wrong (Figure 4).

3.6. Primary Anatomical Success Rate. The primary anatomical success rate after a single operation was $91.6 \%$ and 


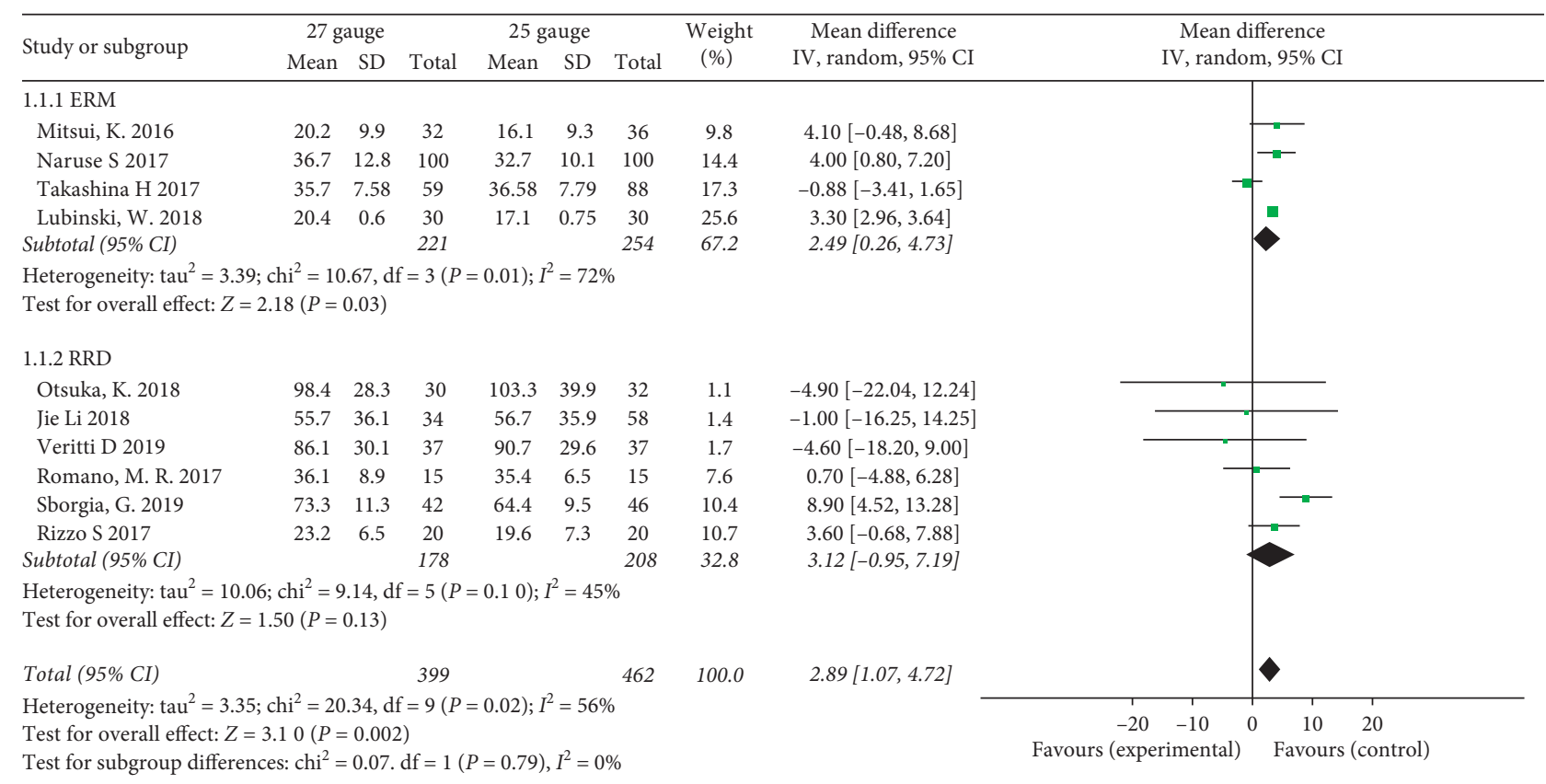

FIGURE 2: Forest plots of operation time compared between 27-G and 25-G vitrectomy in overall and subgroup analysis. RRD: rhegmatogenous retinal detachment; ERM: epiretinal membrane.

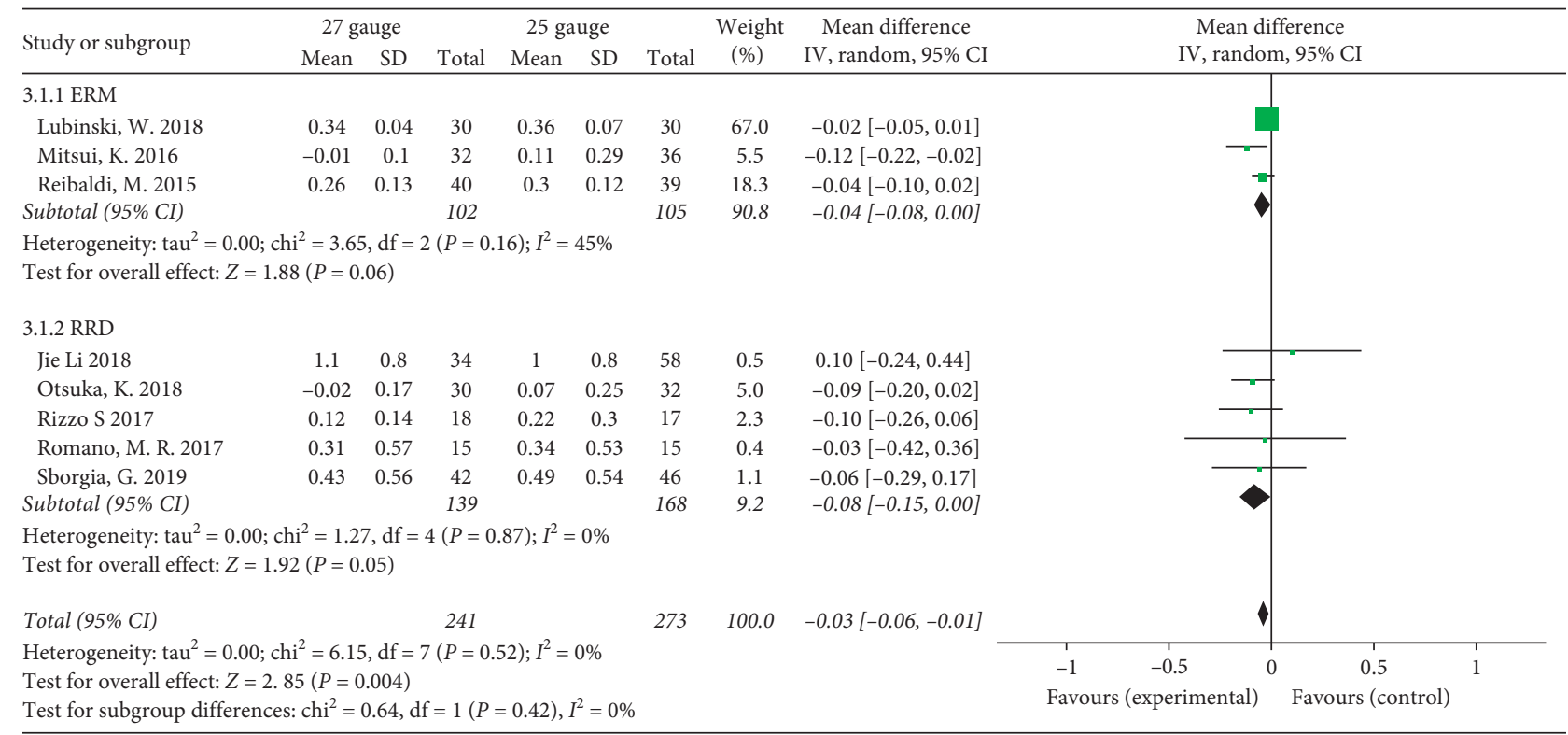

FIGURE 3: Forest plots of best corrected visual acuity (BCVA) compared between 27-G and 25-G vitrectomy at 6 months postoperative in overall and subgroup analysis.

93.3\% in the $25-\mathrm{G}$ and $27-\mathrm{G}$ groups, respectively (Figure 5). The pooled result indicated that there was no significant difference in primary anatomical success rate between $27-\mathrm{G}$ and $25-\mathrm{G}$ group for the treatment of RRD without obvious heterogeneity $\left(\mathrm{OR}=0.8,95 \%\right.$ CI: $\left.0.38,1.71 ; P=0.57 ; I^{2}=0 \%\right)$.

3.7. CMT. Three studies provided information on CMT with at least six months' follow-up. This meta-analysis collected data on CMT at one month (POM1) and six months postoperatively (POM6). The pooled result showed there were no significant differences in CMT for the treatment of ERM between the 25-G and 27-G groups during followup (1 month: $P=0.36$; 6 months: $P=0.18$, resp.) (Figure 6). No heterogeneity was found $\left(I^{2}=0 \%\right)$.

3.8. Intraoperative and Postoperative Complications. Complications in each involved study were summarized in Table 1 . Ten studies (6 on RRD and 4 on ERM) reported 


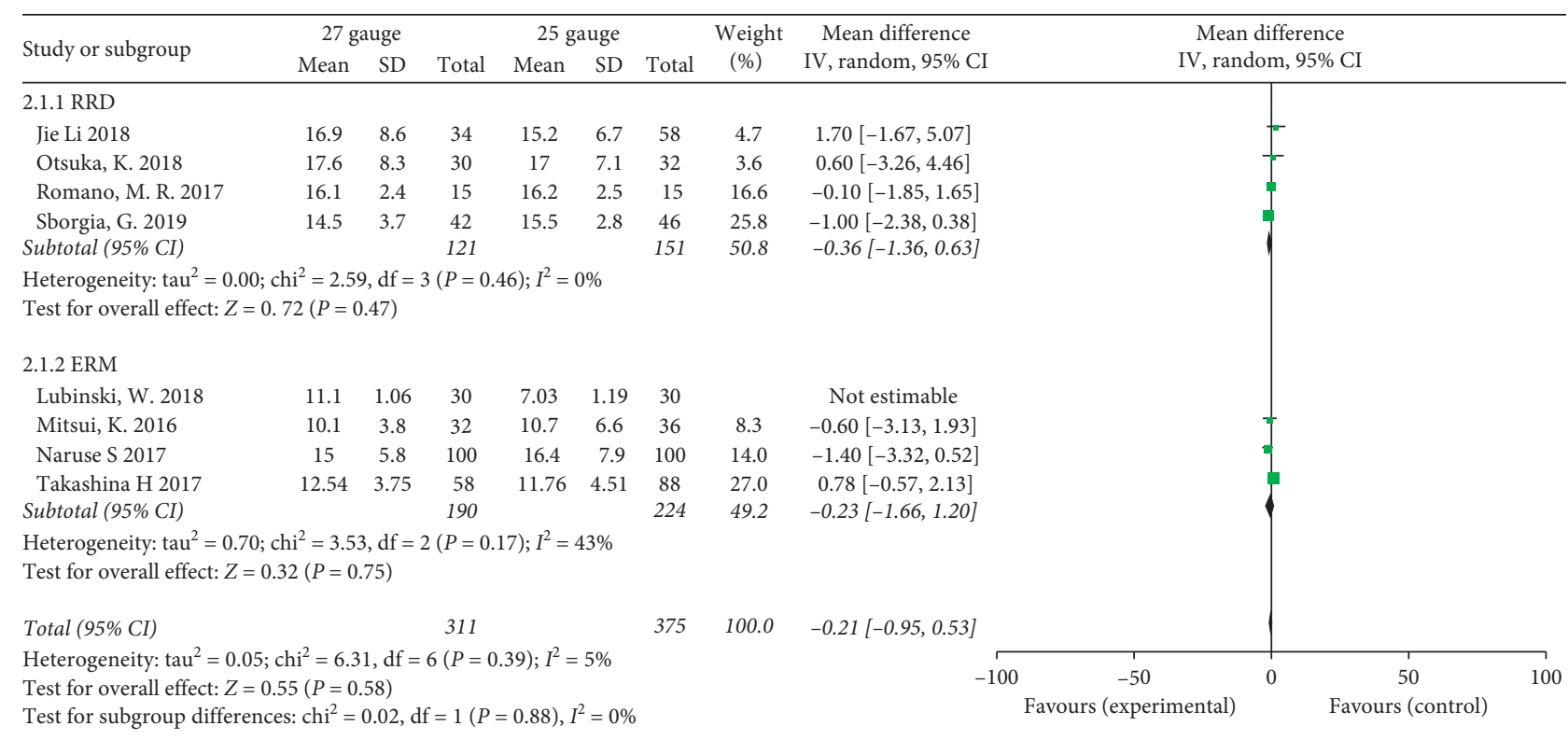

FIGURE 4: Forest plots of intraocular pressure (IOP) at POD1 compared between 27-G and 25-G vitrectomy in overall and subgroup analysis. POD1: postoperative day one.

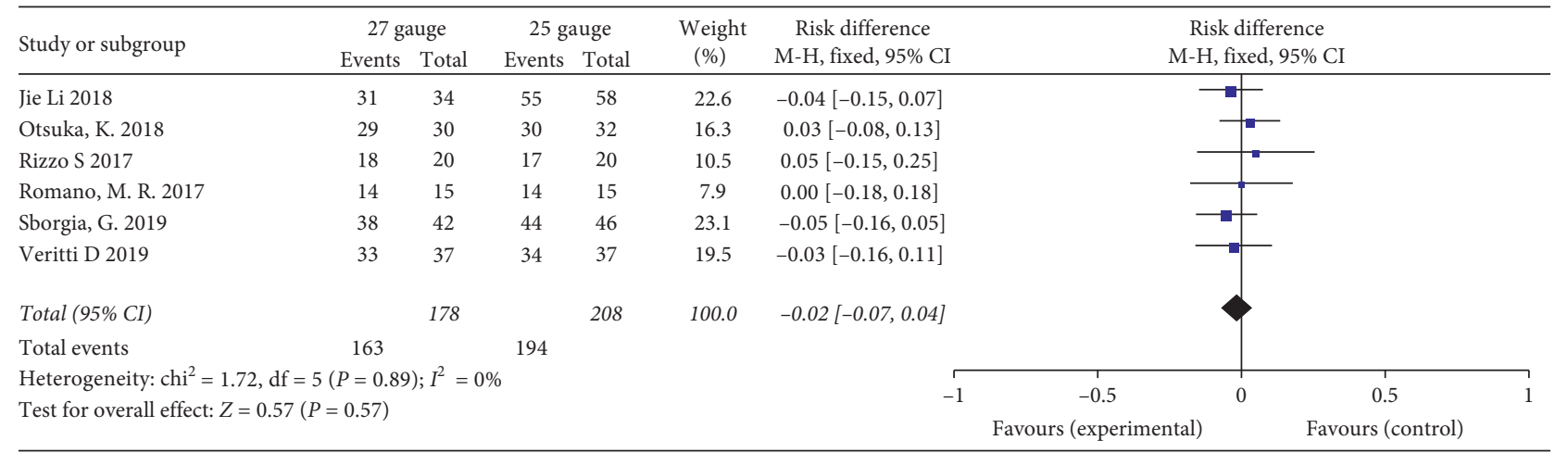

Figure 5: Forest plot of primary anatomical success rate compared between 27-G and 25-G vitrectomy for rhegmatogenous retinal detachment (RRD) cases.

intraoperative and postoperative complications during followup. In the total analysis, 27-G group was associated with less complication compared with the 25-G group with a pooled OR of 0.66 ( $95 \%$ CI: 0.45 to $0.93, P=0.03$ ). However, the difference was not significant in the RRD cases in the subgroup analysis with a pooled OR of 0.86 (95\% CI: 0.52 , $1.44 ; P=0.58)$. No significant heterogeneity was found $\left(I^{2}=29 \%\right)$ (Figure 7$)$.

\section{Discussion}

To the best of our knowledge, this is the first meta-analysis to assess the effectiveness and safety of 27-G MIVS compared with 25-G MIVS for vitreoretinal disease, although only data on the treatment of ERM and RRD were available.

The pooled result illustrated that the time for performing $27-G$ vitrectomy was longer than that for $25-G$ vitrectomy. The difference between the two groups was attributed to the different internal diameters of the vitrectomy probe of the two surgery systems used. Some studies concluded that when comparing 27-G, 25-G, 23-G, and 20-G vitrectomy, more time is required for vitreous excision as the instrument gauge decreases $[9,12]$. However, other studies reported the difference in operation time primarily due to the substantially lower infusion and aspiration rate of the $27-\mathrm{G}$ vitrectomy system used in the present studies but not distinct instrument gauges $[14,15]$. The difference of operation time was significant in the ERM subgroup, but not in the RRD subgroup, which can be explained by three reasons. First, in the RRD surgery, peripheral vitrectomy was more strenuous and complicated than in ERM surgery, and as a result, the operation time mostly depends on the proficiency of surgeon rather than the instrument gauges. Second, Veritti et al. [26] reported that the $27-\mathrm{G}$ probe has excellent fluidics procedures and high cut rate $(7500 \mathrm{cpm})$ and it is very effective in shaving peripheral vitreous for RRD cases, so the operation time was not prolonged by smaller gauge in 27-G group. Third, although the qualities of included studies were 


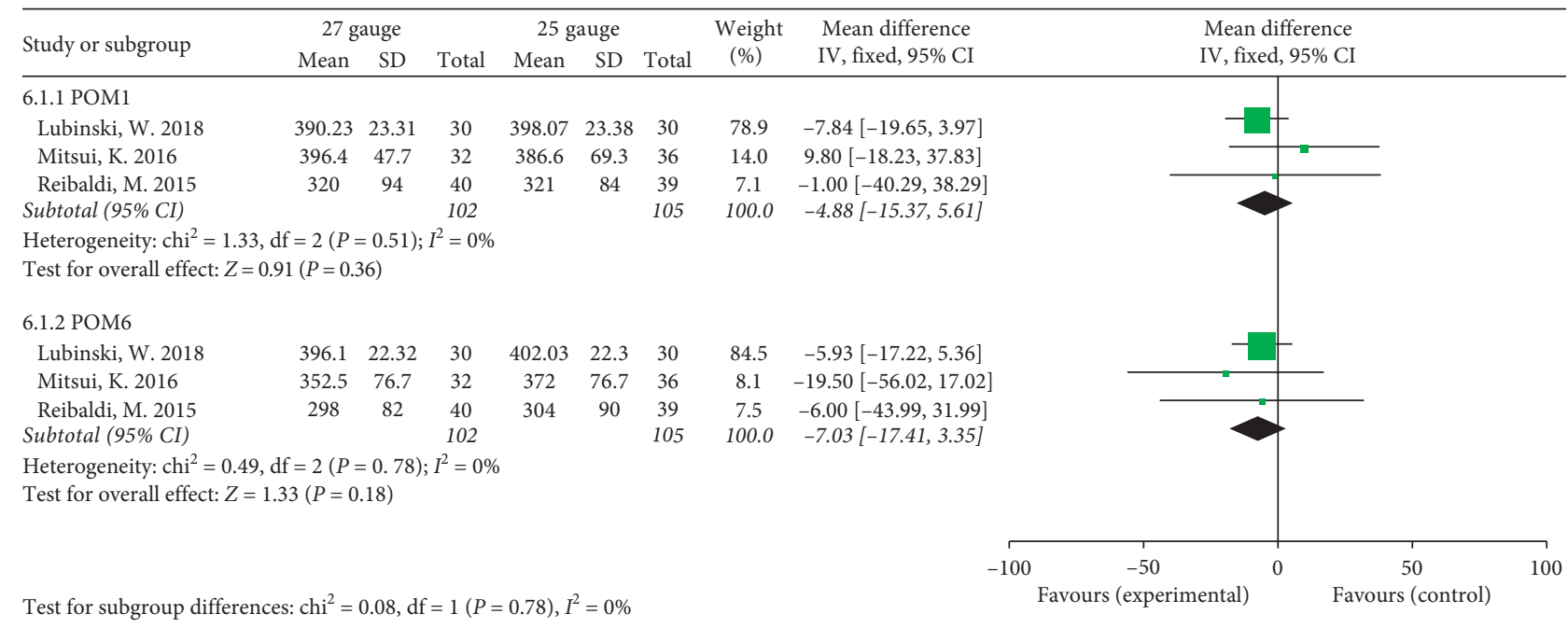

Figure 6: Forest plots of central macular thickness (CMT) at one month and six months postoperatively compared between 27-G and 25-G vitrectomy for epiretinal membrane (ERM) cases.

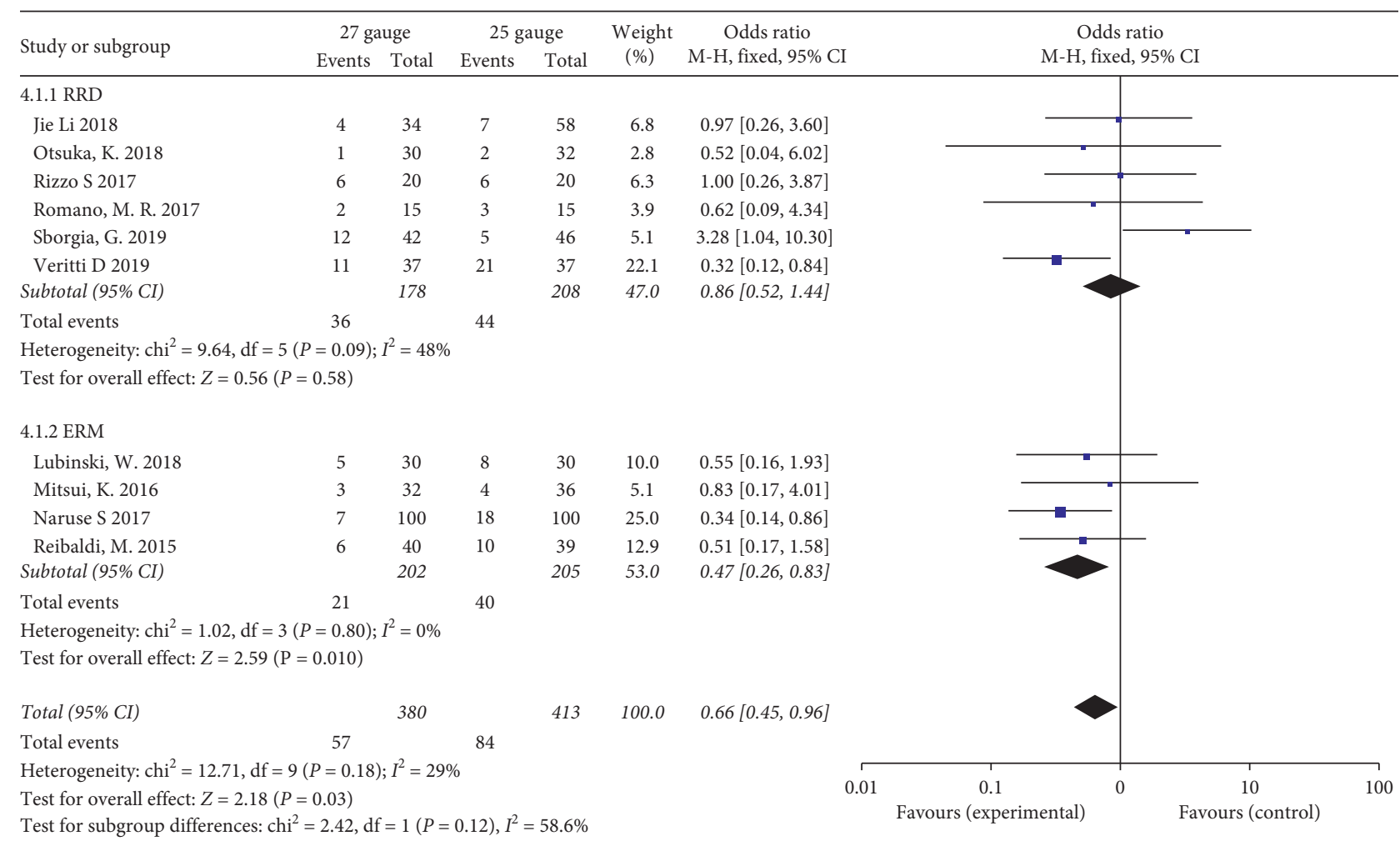

FIGURE 7: Forest plots of intraoperative and postoperative complication between $27-\mathrm{G}$ and $25-\mathrm{G}$ vitrectomy in overall and subgroup analysis. RRD: rhegmatogenous retinal detachment; ERM: epiretinal membrane.

adequate and the sensitive analysis minimized the heterogeneity as much as possible, the heterogeneity in the ERM subgroup may influence the final result.

Regarding the relationship between gauge of instrument and postoperative BCVA, our study showed that BCVA was significantly better in the 27-G group at six months after vitrectomy compared with the $25-\mathrm{G}$ groups. It is hard to explain the reason for this difference. With small gauge vitrectomy, significant inflammation and astigmatism is rarely seen at six months after the operation. For the treatment of RRD, early visual recovery is limited by the using of gas or silicone oil. However, most of the silicone oil was removed before six months after surgery. Also, there were no difference in CMT during followup, so postoperative macular edema should not play a role in visual recovery.

Postoperative IOP at POD1 in 27-G group were as stable as $25-\mathrm{G}$ group. Postoperative hypotony induced by leakage 
of sutureless wound still remains a major complication that can lead to underfilling of tamponade, choroidal detachment, and endophthalmitis. However, Takashina et al. [17] reported that hypotony is usually transient and, in most cases, resolved spontaneously due to small gauge in $27-\mathrm{G}$ vitrectomy. Furthermore, it was suggested that surgeons use oblique incisions and displacement of the conjunctiva to reduce wound leakage and stabilize postoperative IOP.

Operation effectiveness is one of the major theoretical concerns regarding 27-G instrument. Romano et al. [23] reported that the lower flow rate of $27-\mathrm{G}$ system may influence the operation effectiveness. However, Veritti et al. [26] reported that dual pneumatically operated vitrectomy probes of $27 \mathrm{G}$ system with ultrahigh cut rates $(7500 \mathrm{cpm})$ can maintain an efficient vitreous flow rate. For RRD cases, the primary anatomical success rate of included studies ranged from $89 \%$ to $97 \%$ using $27-\mathrm{G}$ and $85 \%$ to $96 \%$ using 25-G MIVS and did not differ significantly between two groups. For ERM cases, there were no differences in postoperative CMT between $27-\mathrm{G}$ and $25-\mathrm{G}$ groups during the six-month follow-up period. This relationship suggests that $1 \mathrm{~mm}$ diameter reduction of sclerotomy in 27-G MIVS, as compared with 25-G MIVS, has no influence on the recovery of normal retinal structure in the vitreoretinal surgery and the $27-G$ was as effective as the $25-G$ system.

Speaking of the safety of the $27-G$ vitrectomy system, besides being less invasive when compared with $25-\mathrm{G}$ system, 27-G carries additional potential advantages; the shorter but flexible vitrectomy probe generates the shortest attraction distance and a smaller "sphere of influence." This allows a more accurate fluid control and a greater dissection precision, theoretically allowing for safer procedures with less intro- and postoperative complications compared with $25-G$ system [26].

The first point of strength in this meta-analysis was that the measurement of outcomes was fairly consistent and pooled results should not be biased due to misclassification. The second point of strength was that the likelihood of bias was minimized by performing a meticulous search for published studies and using explicit methods for study selection, data extraction, quality assessment, and statistical analysis. Third, subgroup and sensitivity analyses were used to confirm the reliability of the pooled results.

This meta-analysis has several potential limitations that should be taken into account. First, the main limitation of this review is the small number of RCTs. Second, we cannot fully exclude publication bias. Third, our analysis was based on only 11 trials, and most of them have a small sample size, which can affect the interpretation of the results. Fourth, some results were limited by heterogeneity between the involved trials.

\section{Conclusions}

In conclusion, our data demonstrated that although $27-\mathrm{G}$ vitrectomy need longer operation time, it had obvious advantages in reducing complications compared with $25-\mathrm{G}$ system for the treatment of ERM. However, these features were not obvious for the treatment of RRD cases.
Multicenter controlled trials should be conducted to determine the overall long-time benefits of $27-G$ vitrectomy for the treatment of all kinds of vitreoretinal disease.

\section{Data Availability}

The data used to support the findings of this study are available from the corresponding author upon request.

\section{Conflicts of Interest}

The authors declare that there are no conflicts of interest regarding the publication of this paper.

\section{Acknowledgments}

This study was financially supported by the National Science Fund from Department of Science and Technology of Qinghai Province (2019-ZJ-7064) and the Fundamental Research Funds for young doctor of Qinghai University (ASRF-2015-YB-07).

\section{References}

[1] R. Machemer, Vitrectomy, a Pars Plana Approach, Grune \& Stratton, New York, NY, USA, 1975.

[2] C. Eckardt, "Transconjunctival sutureless 23-gauge vitrectomy," Retina, vol. 25, no. 2, pp. 208-211, 2005.

[3] G. Y. Fujii, E. De Juan Jr., M. S. Humayun et al., "Initial experience using the transconjunctival sutureless vitrectomy system for vitreoretinal surgery1 1The new Transconjunctival Sutureless Vitrectomy System is disclosed to Bausch \& Lomb Surgical, St. Louis, MO. The Microsurgery Advanced Design Laboratory (MADLAB) may receive royalties related to the sale of this and other instruments mentioned in the article," Ophthalmology, vol. 109, no. 10, pp. 1814-1820, 2002.

[4] G. Y. Fujii, E. De Juan Jr., M. S. Humayun et al., "A new 25gauge instrument system for transconjunctival sutureless vitrectomy surgery1 1The new Transconjunctival Sutureless Vitrectomy System is disclosed to Bausch and Lomb Surgical, St. Louis, MO. The Microsurgery Advanced Design Laboratory (MADLAB) may receive royalties related to the sale of this and other instruments mentioned in the article," Ophthalmology, vol. 109, no. 10, pp. 1807-1812, 2002.

[5] T. Avitabile, F. Castiglione, V. Bonfiglio, and F. Castiglione, "Transconjunctival sutureless 25-gauge versus 20-gauge standard vitrectomy: correlation between corneal topography and ultrasound biomicroscopy measurements of sclerotomy sites," Cornea, vol. 29, no. 1, pp. 19-25, 2010.

[6] H. F. Fine, R. Iranmanesh, D. Iturralde, and R. F. Spaide, "Outcomes of 77 consecutive cases of 23-gauge transconjunctival vitrectomy surgery for posterior segment disease," Ophthalmology, vol. 114, no. 6, pp. 1197-1200, 2007.

[7] K. Kadonosono, T. Yamakawa, E. Uchio, Y. Yanagi, Y. Tamaki, and M. Araie, "Comparison of visual function after epiretinal membrane removal by 20-gauge and 25-gauge vitrectomy," American Journal of Ophthalmology, vol. 142, no. 3, pp. 513-515, 2006.

[8] F. Okamoto, C. Okamoto, N. Sakata et al., "Changes in corneal topography after 25-gauge transconjunctival sutureless vitrectomy versus after 20-gauge standard vitrectomy," Ophthalmology, vol. 114, no. 12, pp. 2138-2141, 2007. 
[9] S. Rizzo, F. Genovesi-Ebert, S. Murri et al., "25-gauge, sutureless vitrectomy and standard 20-gauge pars plana vitrectomy in idiopathic epiretinal membrane surgery: a comparative pilot study," Graefe's Archive for Clinical and Experimental Ophthalmology, vol. 244, no. 4, pp. 472-479, 2006.

[10] H. Shinoda, K. Shinoda, S. Satofuka et al., "Visual recovery after vitrectomy for macular hole using 25-gauge instruments," Acta Ophthalmologica, vol. 86, no. 2, pp. 151-155, 2008.

[11] Y. Inoue, K. Kadonosono, T. Yamakawa et al., "Surgicallyinduced inflammation with 20-, 23-, and 25-gauge vitrectomy systems," Retina, vol. 29, no. 4, pp. 477-480, 2009.

[12] O. Sandali, M. El Sanharawi, N. Lecuen et al., "25-, 23-, and 20-gauge vitrectomy in epiretinal membrane surgery: a comparative study of 553 cases," Graefe's Archive for Clinical and Experimental Ophthalmology, vol. 249, no. 12, pp. 18111819, 2011.

[13] A. Haas, G. Seidel, I. Steinbrugger et al., "Twenty-three-gauge and 20-gauge vitrectomy in epiretinal membrane surgery," Retina, vol. 30, no. 1, pp. 112-116, 2010.

[14] Y. Oshima, T. Wakabayashi, T. Sato, M. Ohji, and Y. Tano, "A 27-gauge instrument system for transconjunctival sutureless microincision vitrectomy surgery," Ophthalmology, vol. 117, no. 1, pp. 93-102, 2010

[15] K. Mitsui, J. Kogo, H. Takeda et al., "Comparative study of 27gauge vs 25-gauge vitrectomy for epiretinal membrane," Eye, vol. 30, no. 4, pp. 538-544, 2016.

[16] S. Rizzo, F. Barca, T. Caporossi, and C. Mariotti, "Twentyseven-gauge vitrectomy for various vitreoretinal diseases," Retina, vol. 35, no. 6, pp. 1273-1278, 2015.

[17] H. Takashina, A. Watanabe, and H. Tsuneoka, "Perioperative changes of the intraocular pressure during the treatment of epiretinal membrane by using 25 - or 27-gauge sutureless vitrectomy without gas tamponade," Clinical Ophthalmology, vol. 11, pp. 739-743, 2017.

[18] M. A. Khan, W. A. Samara, J. Hsu, and S. Garg, "Short-term outcomes of hybrid 23-, 25-, and 27-gauge vitrectomy for complex diabetic tractional retinal detachment repair," Retinal Cases \& Brief Reports, vol. 13, no. 3, pp. 244-247, 2019.

[19] M. A. Khan, A. Shahlaee, B. Toussaint et al., "Outcomes of 27 gauge microincision vitrectomy surgery for posterior segment disease," American Journal of Ophthalmology, vol. 161, pp. 36-43.e2, 2016

[20] R. Ho, S. Naruse, and H. Shimada, "Comparative study of 27gauge and 25-gauge vitrectomy performed as day surgery," International Ophthalmology, vol. 38, no. 4, pp. 1575-1582, 2018.

[21] M. Reibaldi, A. Longo, T. Avitabile et al., "Transconjunctival nonvitrectomizing vitreous surgery versus 25 -gauge vitrectomy in patients with epiretinal membrane," Retina, vol. 35, no. 5, pp. 873-879, 2015.

[22] S. Mariotti, S. Polizzi, F. Barca, T. Caporossi, and G. Virgili, "Comparative study of 27 -gauge versus 25 -gauge vitrectomy for the treatment of primary rhegmatogenous retinal detachment," Journal of Ophthalmology, vol. 2017, Article ID 6384985, 5 pages, 2017.

[23] M. R. Romano, G. Cennamo, M. Ferrara, M. Cennamo, and G. Cennamo, "Twenty-Seven-gauge versus 25-gauge vitrectomy for primary rhegmatogenous retinal detachment," Retina, vol. 37, no. 4, pp. 637-642, 2017.

[24] W. Lubinski, W. Goslawski, K. Podboraczynska-Jodko, M. Mularczyk, and M. Post, "Comparison of 27-gauge versus 25-gauge vitrectomy results in patients with epiretinal membrane: 6-month follow-up," International Ophthalmology, vol. 40, no. 4, pp. 867-875, 2020.

[25] K. Otsuka, H. Imai, A. Fujii et al., "Comparison of 25- and 27gauge pars plana vitrectomy in repairing primary rhegmatogenous retinal detachment," Journal of Ophthalmology, vol. 2018, Article ID 7643174, 5 pages, 2018.

[26] D. Veritti, V. Sarao, and P. Lanzetta, "A propensity-score matching comparison between 27 -gauge and 25-gauge vitrectomy systems for the repair of primary rhegmatogenous retinal detachment," Journal of Ophthalmology, vol. 2019, Article ID 3120960, 6 pages, 2019.

[27] S. H. Downs and N. Black, "The feasibility of creating a checklist for the assessment of the methodological quality both of randomised and non-randomised studies of health care interventions," Journal of Epidemiology \& Community Health, vol. 52, no. 6, pp. 377-384, 1998.

[28] J. P. T. Higgins, S. G. Thompson, J. J. Deeks, and D. G. Altman, "Measuring inconsistency in meta-analyses," BMJ, vol. 327, no. 7414, pp. 557-560, 2003.

[29] S. Naruse, H. Shimada, and R. Mori, "27-gauge and 25-gauge vitrectomy day surgery for idiopathic epiretinal membrane," BMC Ophthalmology, vol. 17, no. 1, p. 188, 2017.

[30] J. Li, B. Zhao, S. Liu, F. Li, W. Dong, and J. Zhong, "Retrospective comparison of 27 -gauge and 25 -gauge microincision vitrectomy surgery with silicone oil for the treatment of primary rhegmatogenous retinal detachment," Journal of Ophthalmology, vol. 2018, Article ID 7535043, 7 pages, 2018.

[31] G. Sborgia, A. Niro, L. Sborgia et al., "One-year outcomes of 27 -gauge versus 25 -gauge pars plana vitrectomy for uncomplicated rhegmatogenous retinal detachment repair," International Journal of Retina and Vitreous, vol. 5, p. 13, 2019. 